\title{
AUTOTUTELA, SOLUCIÓN ADECUADA DEL CONFLICTO Y REPOSSESSION: REVISIÓN Y PROPUESTA*
}

\author{
JORDI DELGADO CASTRO** \\ Diego PALOMO VÉLEZ ${ }^{* * *}$ \\ GERMÁN DELGADO ${ }^{* * * *}$
}

RESUMEN: El presente trabajo realiza una revisión acerca de las principales características y elementos que rodean a la institución de la autotutela en nuestro entorno, como un método de resolución del conflicto. Efectivamente, con carácter general se trata de una forma proscrita de solucionar un diferendo jurídico y pretendemos, de algún modo, señalar su conveniencia en algunos casos. De esta revisión se concluye que el principal elemento, que permite señalar una prohibición general de uso como método de resolución del conflicto, es la violencia. Adicionalmente, se describe y propone adoptar entre nosotros una figura autotutelar: la repossession.

\section{PALABRAS CLAVE: Autotutela; Reposesión; Repossession}

\section{SELF-HELP APPROPRIATE DISPUTE RESOLUTION AND REPOSSESSION: REVIEW AND PROPOSAL}

ABSTRACT: This paper reviews the main features and elements surrounding self-help remedies in our legal system, as conflict resolution method. While, in general, self-help remedies are forbidden, the authors consider that they might be an effective remedy in some instances. From this review, we conclude that the main element in banning self-help rem-

\footnotetext{
* Este trabajo corresponde a parte de los resultados del Proyecto financiado por el Programa de Investigación Asociativa (PIA), Anillo SOC No 1406: "Mecanismos alternativos de resolución de conflictos como herramienta de modernización de la justicia. Construcción dogmática a partir de un análisis multidisciplinario”.

Fecha de recepción: 5 de abril de 2016.

Fecha de aceptación: 22 de julio de 2016.

** Profesor de Derecho Procesal, Universidad de Talca (Chile). Doctor en Derecho, Universidad de Barcelona, Espańa. Correo electrónico: jdelgado@utalca.cl

*** Profesor de Derecho Procesal, Universidad de Talca (Chile). Doctor en Derecho, Universidad Complutense de Madrid, España. Correo electrónico: dpalomo@utalca.cl

**** Abogado, LL.M. Duke University Law School (EE.UU.).
} 
edies as a method of conflict resolution, is violence. Additionally, we describe and propose to adapt a specific self-help remedy: repossession.

KEYWORDS: Self; Help; Repossession; Repo

Sumario: Introducción. 1) El conflicto y la autodefensa. 2) ¿Qué es lo que realmente se prohibe? 3) Autotutela permitida: Excepciones a la prohibición de autotutela. 4) Reposesión: Una propuesta de autotutela. 5) Autotutela del acreedor en nuestro ordenamiento jurídico. 6) Repossession, autotutela y nuestro ordenamiento jurídico (a modo de conclusión). Bibliografía.

\section{INTRODUCCIÓN}

Es habitual entre la dogmática procesal comenzar la explicación del concepto jurisdicción ${ }^{1}$ caracterizando, en primer lugar, el conflicto y sus formas de solución. Es, probablemente, la forma más lógica de poder exponer con claridad que entre las diversas soluciones, la que prefiere la ciencia procesal es la que fundamenta su objeto de estudio.

También es común dar un tratamiento a las otras formas de resolución del conflicto vago y superficial, sin detener esfuerzos en considerar aquellas otras soluciones como, quizá, más efectivas que el proceso ${ }^{2}$.

Reconociendo esta carencia, el objetivo de este trabajo es realizar un estudio avanzado sobre el concepto de la autotutela como medio de resolución del conflicto, para finalmente, observar un modelo de derecho comparado, como propuesta para nuestro proceso civil.

\section{1) EL CONFLICTO Y LA AUTODEFENSA}

Tradicionalmente, se ha destacado que el ser humano al vivir en sociedad está expuesto a que se generen conflictos propios de la conviven-

1 Así, baste como ejemplos clásicos: Goldschmidt, James (1936) Derecho procesal civil. Traducción Prieto Castro. Barcelona: Editorial Labor, 935 pp.; Rosenberg, Leo (1955) Tratado de Derecho procesal civil. Traducción Romero Vera. Buenos Aires: Ediciones Jurídicas EuropaAmérica, 512 pp.

2 Reivindicación que viene desde antiguo puesto que a una reflexión similar llega Alcalá ZAMOrA: "Las mayores dudas las origina la autodefensa, inmenso territorio que los procesalistas apenas si han explorado. Cierto que en numerosos libros procesales se presenta el proceso como sustitutivo y sucesor de la autodefensa, pero ni esa tesis está a cubierto de reservas, según veremos en la conferencia inmediata (cfr. núms. 25, 27, 28 Y 40), ni, sobre todo, el desarrollo, episódico e incidental, de semejante idea, suele pasar de unas pocas líneas, circunscritas a mencionar sus cinco o seis expresiones más conocidas, sin preocuparse siquiera de fijar el concepto de autodefensa ni de establecer sus repercusiones e interferencias con el proceso". (Alcalá Zamora, Niceto (2000) Proceso, autocomposición y autodefensa. Contribución al estudio de los fines del proceso. México D.F: Universidad Nacional Autónoma de México, 314 pp., p. 23). 
cia $^{3}$. Es ahí, donde el Derecho ha de entregar una mejor gestión de aquellas divergencias que permita el mantenimiento de la paz. Sin embargo, es inevitable que existan conflictos intersubjetivos de intereses jurídicos que irremediablemente pueden quebrar la armonía necesaria, para la convivencia democrática. En este contexto de tensión es que el Derecho procesal ha dispuesto de su mejor mecanismo -el proceso- como garante de la pacífica relación de los miembros de una comunidad ${ }^{4}$.

En este escenario conflictual, el Estado asume la resolución de las desavenencias mediante el establecimiento de órganos independientes e imparciales que se pronuncian sobre el supuesto de hecho concreto. De este modo, se prohíbe -en términos generales- la justicia por la propia mano entregándose los mecanismos suficientes para conseguir el objetivo final que no es otro que el mantenimiento de la paz social 5 .

De hecho es, precisamente, esta una de las características más clásicas del Derecho procesal, de la acción, o cualquier lección introductoria sobre el tema. Entre nuestra doctrina ${ }^{6}$ más autorizada y fundamental se destaca como algo positivo, "normal" y deseable el hecho que los particulares no pueden ejercer una gestión directa del conflicto sin la intervención del Estado que dicta las normas. Este principio básico pervive hasta nuestros

3 Magistralmente, explicaba Carnelutti que "Cuando los conflictos de intereses pertenecen a personas distintas (conflicto intersubjetivo), su incompatibilidad constituye un peligro, pero no todavía un daño para la paz, ya que puede ocurrir o que uno de los interesados tolera la insatisfacción o entre ellos medie un acuerdo. El peligro se transforma en daño cuando, no verificándose ninguna de las hipótesis recién imaginadas, los interesados pasan a ser contendientes en cuanto cada uno de ellos exige se satisfaga su interés" (CARnELUTTI, Francesco (1973) Instituciones del Proceso Civil. Traducción Sentís Melendo, Vol. 1. Buenos Aires: Ediciones Jurídicas Europa-América, 557 pp., p. 25).

4 Perfectamente lo explica Colombo Campbell: "El conflicto de intereses de relevancia jurídica surge cuando una persona pretende de otra la satisfacción de algunas de sus necesidades y esta que debe procurarle los medios, se resiste porque a su vez hacerlo afecta a sus intereses. Estos adquieren relevancia jurídica cuando los intereses en conflicto se encuentran protegidos por el derecho" (Соцомво Campbell, Juan (1997) Los actos procesales. Tomo I. Santiago: Editorial Jurídica de Chile, 333 pp., p. 151).

5 En parecidos términos se ha observado por la doctrina clásica desde antaño. Así, Alsina, Hugo (2001) Fundamentos de Derecho Procesal, Vol. 4. México D.F.: Editorial Jurídica Universitaria, 583 pp., p. 8: "Correspondiendo al Estado resolver las controversias entre particulares cuando éstos no logren una solución pacífica, ha debido para ello, según hemos visto, crear órganos especiales, fijar sus atribuciones para establecer las reglas de actuación. Al prohibir a sus súbditos hacerse justicia por propia mano, el Estado asume la tutela de sus derechos arrogándose la jurisdicción”.

6 Un ejemplo paradigmático entre nosotros, pudiera ser Couture quien, está fuera de toda duda el nivel de influencia de sus postulados. Así por ejemplo, explica: "Cuando el hombre se siente objeto de una injusticia, de algo que él considera contrario a su condición de sujeto de derechos, no tiene más salida que acudir ante la autoridad. Privado ya de su poder de hacerse justicia por mano propia, le queda en reemplazo el poder jurídico de requerir la colaboración de los poderes constituidos por el Estado". (Couture, Eduardo (1989) Estudios de Derecho Procesal Civil. Tomo I, La Constitución y el Proceso Civil, $3^{\text {a }}$ Ed. Buenos Aires: Ediciones Depalma, 366 pp., p. 28. 
días y de hecho es un $\operatorname{dogma}^{7}$ que, en demasiadas ocasiones, produce que los procesalistas no sean capaces de asumir a los métodos alternativos de solución de controversias (MASC) como una salida tan deseable como el proceso.

Principalmente, siempre se aduce a que el avance de la civilización nos lleva a una preferencia por la solución pacífica de los conflictos y, por lo tanto, los particulares deben abandonar cualquier iniciativa que importe el uso de la violencia, en favor del Estado que, dotado de los poderes suficientes, debe responder al ejercicio de la Justicia ${ }^{8}$.

Paradójicamente esta concepción sufrió cuestionamientos serios durante el siglo XIX. En una época marcada por postulados liberales y por la máxima que las partes eran las "dueńas del proceso" hay un cierto recelo hacia la actividad Estatal que no se corregirá hasta la llegada de la llamada publicización del proceso y la Ordenanza Procesal de Klein. En esta corriente renovadora, se confía de mayor forma en los jueces a quien, a partir de entonces, se les concede el papel de gestores del proceso, con mayores poderes que, a la postre, redundan en una mejor protección de la sociedad en su conjunto?.

Pero en términos generales, finalmente, la doctrina reconoce que la acción directa está prohibida y que cuando los particulares no son capaces de arribar a una solución por sí mismos en forma espontánea, deberán so-

7 Modernamente, la doctrina nacional sostiene en sus visiones contemporáneas de la jurisdicción, algunos conceptos que continúan siendo los mismos que los clásicos postularon. Así por ejemplo: Núñez Ojeda, Raúl y Pérez Ragone, Álvaro (2013) Manual de Derecho Procesal Civil. Parte General. Santiago: Thomson Reuters, 486 pp., p. 67: "Como la tutela del derecho material no puede ser buscada privadamente, ella es postulada de forma jurisdiccional a través del ejercicio de la acción. Es en esa dimensión, que se afirma que el estado tiene el deber de darle tutela a los derechos, teniendo la judicatura la obligación de prestarla”.

8 En este mismo sentido, desde los mismos postulados de Derecho Romano, se nos señala: "En un ambiente social primitivo, donde falta un poder de coacción que impela al cumplimiento de los que son tenidos por derechos, bien se comprende que constituya la autodefensa el único medio del que pueda valerse la parte acreedora, sea por contrato o sea por delito, para obligar a la parte deudora a la observancia de sus deberes jurídicos. Mas cuando el Estado ha surgido, son sus órganos - los Tribunales- los que asumen la defensa para la aplicación de las sanciones correspondientes a tales deberes. Fuera de los casos de legítima defensa, singularmente reconocida en situaciones de agresión actual o presente e injustificada, y de fundada sospecha de huida del autor o deudor, la única vía es la jurídica para encontrar la protección de cualquier derecho, con la consiguiente ejecución coactiva del deber que encierra. En la época augustea se dan leyes encaminadas a condenar el uso de la violencia para la propia defensa de los derechos. Luego, en la época imperial, un decreto de Marco Aurelio -decretum divi Marci-, favoreciendo con nueva acogida en la legislación posterior, establece una sanción civil, por virtud de la cual pierde su derecho aquel que puse en práctica medios de propia defensa o ejecución, e incurre en la obligación de restituir, por razón del duplo, el que exige y adquiere, mediante igual procedimiento, algo para lo que no tiene título jurídico" (Iglesias, Juan (2001) Derecho Romano, 13 $3^{\text {a }}$ Ed. Madrid: Ariel, 520 pp., p. 118).

9 Montero Aroca, Juan (2006) La nueva Ley de Enjuiciamiento Civil española, los poderes del juez y la oralidad. Valencia: Tirant lo Blanch, 438 pp., pp. 71-72. 
lucionar sus problemas ante la Administración de Justicia ${ }^{10}$. Sin embargo, hay que contextualizar estas notas dentro del concepto jurisdicción: De este modo, entenderemos que se trata de una función pública radicada en jueces. Pareciera un concepto sencillo, pero la tensión entre lo público y privado $^{11}$ de la jurisdicción, lejos de ser un tema pacífico, importa para que la doctrina le reconozca un valor mayor o menor a los MASC ${ }^{12}$.

La autodefensa, autotutela o autoayuda ${ }^{13}$ ha sido bien definida como un medio de solución del conflicto directo y unilateral mediante el que una parte no acepta subordinar su interés propio al ajeno y hace uso de la fuerza, en atención a que la espera de la solución mediante el proceso significaría la aceptación de un daño que teme se pueda dar ${ }^{14}$.

Calamandrei acertadamente señalaba que la base de los conceptos jurisdicción y acción residen en la premisa del Estado moderno que prohíbe la autodefensa ${ }^{15}$. Esta forma de entender la resolución del conflicto va a resultar de capital importancia para que, hasta nuestros días, la tradición continental tenga una concepción relativamente escéptica hacia los MASC $^{16}$

Es interesante revivir la explicación de Calamandrei puesto que nos hace comprender varias cosas. En primer lugar, la prohibición de autodefensa es fruto de una larga evolución. Además, significa que quien goza de un derecho subjetivo amparado por la ley, no puede poner en obra

10 Serra Domínguez, Manuel (2008) Jurisdicción, acción y proceso. Barcelona: Atelier, 260 pp., p. 17.

11 De hecho, Carnelutti hablará del desempeño privado de una función pública. (CARnelutti (1979) 356).

12 Así, por ejemplo resultan diáfanas ciertas reflexiones de TARUfFo a propósito de una relectura de los postulados de Ferrajoli. Señala, así en relación a la caracterización de la jurisdicción como garantía realizada por Ferrajoli que: "Este marco tiene, en efecto, la ventaja de establecer con claridad cuál es la función fundamental de la jurisdicción como instrumento indispensable de la actuación del Derecho. De un lado, esto implica prescindir de formulistas corrientes como aquellas según las cuales la justicia sería un servicio, o un negocio, o una rama de la administración pública, y así por el estilo, que constituyen una línea de devaluación de la jurisdicción y que se combina con la exaltación de las distintas formas de justicia "privada", como si la verdadera justicia la hicieron los árbitros (escogidos y pagados por apartes) y no los jueces (preconstituidos por la ley y no remunerados por sus "usuarios")". Véase, TARuffo, Michele (2009) Páginas sobre justicia civil. Madrid Barcelona Buenos Aires: Marcial Pons, 599 pp., p. 22.

13 Resultan altamente interesantes las consideraciones realizadas a cada una de estas voces por Alcalá Zamora (2000) 47-50.

14 En parecidos términos, Alvarado Velloso, Adolfo y Aguila Grados, Guido (2011) Lecciones de Derecho Procesal Civil. Lima: Editorial San Marcos, 838 pp., p. 5.

15 Calamandrei, Piero (1973) Instituciones de Derecho Procesal Civil. Buenos Aires: Ediciones Jurídicas Europa-América, 421 pp., p. 222.

16 En realidad, ese escepticismo también fuera punto de partida en ordenamientos anglosajones, como el estadounidense que de entenderlos como mecanismos de segunda categoría, pasarán a ser la primera fuente de solución del conflicto: Twining, William (1993) "Alternative to What? Theories of Litigation, Procedure and Dispute Settlement in Anglo-American Jurisprudence: Some Neglected Classics". The Modern Law Review, 56:3, pp. 380-392. 
la fuerza privada para hacerlo valer ${ }^{17}$. Puesto, y esto podría ser lo más relevante, que el Estado moderno prohíbe la autodefensa, en tanto el derecho individual está protegido por él mismo y no por la fuerza privada. En contraste a ello, es necesario señalar que Alcalá Zamora ${ }^{18}$ tras una magistral construcción del concepto, y prefiriendo el término autotutela, consigue demostrar que, en resumen, la autotutela se caracteriza por la ausencia de un juez y la imposición de la solución por una de las partes. En consecuencia, siguiendo esta línea argumental, hay una clara ausencia de cualquier organización para la resolución del conflicto, pero no encontraríamos, necesariamente, el uso de la fuerza física como elemento diferenciador de esta institución.

El fundamento, que sigue entregando CALAMANDrei ${ }^{19}$, pasa por algo ya señalado. La sociedad cuando más avanzada se estructura en asociaciones mayores a los individuos, por lo tanto, una autoridad superior debe ser la encargada de resolver los conflictos entre los socios ${ }^{20}$. Los individuos, en este escenario, no son el ente más apto para resolver los conflictos, aunque les reconoce dos formas en que pueden llegar a acuerdo: o bien por un acuerdo voluntario (contrato) que establezca cómo superar la desavenencia; o bien, la fuerza privada, autodefensa o defensa privada que junto con ser un medio primitivo, se asemeja a la guerra entre la resolución de conflictos entre Estados. Por lo tanto, resulta una forma totalmente desaconsejable.

La segunda forma propuesta por CALAMANDrei ${ }^{21}$, la fuerza privada, resulta claramente desestimada por el profesor fundamentando que, en realidad, constituye una negación del derecho y de la convivencia pacífica; que nadie puede ser juez en su propia causa y que, en definitiva, no siempre la prepotencia del más fuerte se va a corresponder con la decisión más justa.

En esta misma línea argumentativa y, como ya se dijo, la autodefensa se entiende como una forma primitiva y las legislaciones van a ir prohibiendo y tipificando como delito. Como señalaba Calamandrei, mediante una evolución puesto que en algún momento se reguló el uso de la fuerza ${ }^{22}$. En algunas ocasiones, el Estado no condena el uso de la fuerza, siempre que antes se acuda a juicio para saber qué parte tiene la

Calamandrei (1973) 222.

Alcalá Zamora (2000) 53.

Calamandrei (1973) 223.

En un escenario parecido, se nos explica con acierto que, sin saber exactamente en qué momento histórico se pasó de preferir la fuerza por la razón, cuando sucedió aquello "se aceptó por todo los coasociados la posibilidad de dialogar para intentar lograr la autocomposición pacífica de los conflictos, sin uso de armas o fuerza" (Alvarado Velloso y Aguila Grados (2011) 5).

21 Calamandrei (1973) 223.

22 Como en los duelos de caballeros (Calamandrei (1973) 224). 
razón; o bien, algunas civilizaciones han ido regulando una prohibición general, con concretas excepciones, en especial, el mejor ejemplo siempre recurrente es la legítima defensa.

La conclusión a la que llega Calamandrei es que la autodefensa aparece como una prohibición general heredada del Derecho romano que en la época medieval y moderna va desapareciendo progresivamente (los germanos impusieron métodos como la venganza y el duelo) y que será el Derecho canónico el que restablezca esa prohibición, en forma general y absoluta, puesto que en esta característica se sustenta el "edificio constitucional del Estado de Derecho"23.

Desde ese punto de vista, procesal y constitucional, la mejor doctrina ha considerado que la autotutela puede conllevar graves consecuencias porque en una sociedad existen muchos sujetos que no están en condiciones de defenderse a sí mismos y, por otra parte, porque en el desarrollo de la autodefensa muchas son las ocasiones en que la fuerza excede lo necesario y genera más tensión para el futuro ${ }^{24}$.

En términos muy simples el fenómeno pasa por ir reduciendo los espacios de autodefensa $y$, a su vez, ir aumentando el poder e injerencia de fuerza pública del Estado, de modo que sea este quien defienda los Derechos de sus súbditos, como medio de evitar que sean los propios ciudadanos quienes defiendan sus derechos privados. Para conseguir que este objetivo sirva a la paz social se debe sustraer el conflicto de las partes y entregar su solución a un tercero desinteresado e imparcial ${ }^{25}$. En una escala gradual, el Estado comenzará a fomentar el arbitraje ante un tercero como resolutor de la contienda para, finalmente, adoptar aquella función como propia mediante jueces de carácter público a los que se obligará a acudir, para solucionar el conflicto.

En conclusión, y atendiendo todavía lo señalado por CalamanDREI $^{26}$, el Estado progresivamente va a restringir cada vez más, hasta prohibirla, la autodefensa, mientras perfecciona la organización y medios entregados a los ciudadanos para una defensa pública de sus intereses ${ }^{27}$.

23 Calamandrei (1973) 225. Finalmente, Calamandrei expone los casos en que se castiga como delito la tutela arbitraria de derechos propios: "comprende los delitos de "ejercicio arbitrario de los derechos propios" (arts. 392, 393 C.p. y de "desafío a duelo" y "uso de armas en duelo (arts. 394, 396). Particularmente significativas, en relación a cuanto se ha dicho hasta ahora, son las disposiciones concernientes al delito de ejercicio arbitrario de los derechos propios, el cual se manifiesta cuando alguien "a fin de ejercitar un pretendido derecho, pudiendo recurrir al juez" se hace arbitrariamente justicia por sí mismo con violencia sobre las cosas o sobre las personas".

24 Vallespín PÉrez, David (2002) El modelo constitucional de juicio justo en el ámbito del proceso civil. Barcelona: Atelier, 170 pp., p. 107.

25 Calamandrei (1973) 226-227.

26 Calamandrei (1973) 228-229.

27 Con la misma esencia, VAllespín PÉREz (2002) 107: "En la lenta evolución hacia la sustitución del juicio de la parte por el juicio del juez adquiere un especial relieve la aparición del Estado de Derecho. Se reduce al máximo la posibilidad de autotutela, propugnándose la utilización de 
Pero la autodefensa no solamente se puede dar en las relaciones entre particulares. La doctrina ha señalado varios ámbitos en que la autotutela se prohíbe en beneficio de la sociedad. Así, cuando la violencia lleva a actos de autotutela a sujetos privados contra el Estado; también se contempla la nulidad de los actos que se sigan la vía de hecho entre autoridades o poderes públicos; $\mathrm{Y}$, pese a que no pareciera ser lo óptimo, las relaciones entre Estados, muchas veces se solucionan de forma autodefensiva ${ }^{28}$.

\section{2) ¿QUÉ ES LO QUE REALMENTE SE PROHÍBE?}

Probablemente nos encontramos ante el centro de una cuestión que no resulta, en absoluto, baladí. Generalmente, se prohíbe el uso de la fuerza y se explica como si la fuerza, solamente, importara una sanción penal, o se desarrollara en un contexto penal. Esta forma de ver la prohibición de la autotutela introduce un sesgo que, pareciera, imposibilitar cualquier tipo de acción que implique un uso físico razonable o una consecuencia civil ${ }^{29}$.

De modo que, finalmente, se trata de una temática carente de una fundamentación clara, más allá de máximas de común deseo y entendimiento. El punto de partida clásico y paradigmático pudiera ser la descripción bélica que realiza CARnelutTi. Efectivamente, nadie está en favor de la guerra y el imperio del Derecho, precisamente, está para hacerle la guerra a la guerra ${ }^{30}$. Entonces, la prohibición de la autotutela o autodefensa, pasa por la prohibición de la guerra.

fórmulas autocompositivas y heterocompositivas para la resolución de los litigios cuando ello fuere posible y, en último término, la posibilidad de acudir al proceso”.

28 Colombo Campbell (1991) 13.

29 En ocasiones, el soslayo de la expresión violencia, en favor de otras, quizá nos conduce a generar confusión. Es decir, cuando, por ejemplo, Serra Domínguez (2008) 17, señala que lo que se prohíbe "incluso penalmente" es el ejercicio de la acción directa y específica que la realización arbitraria del propio derecho presupone la existencia de un derecho y termina convirtiéndose en un delito contra la Administración de justicia, genera una imagen que puede llevar a confusión. Puesto que, en puridad, lo que se sanciona es la violencia asociada a estos fenómenos y no los objetivos perseguidos con las acciones.

30 Carnelutti, Francesco (2001) Cuestiones sobre el proceso penal, Vol. 2. México D.F.: Editorial Jurídica Universitaria, 265 pp., p. 16. Especialmente interesante para estos fines resultan las sabias palabras: "El primado histórico es naturalmente el reflejo del primado lógico: la primera medida para combatir la guerra es prohibirla. Y la guerra prohibida se llama delito. Solamente porque los delitos individuales perdieron a lo largo de los siglos, su carácter original, no hablamos ya de guerra sino entre los pueblos; pero lo que llamamos guerra no es más que un asesinato y un latrocinio colectivo y lo que se llama homicidio o hurto no es más que una guerra individual. Pero a fin de combatir la guerra no basta prohibirla. La guerra originariamente no sirve tan solo para desarrollar sino también para limitar el egoísmo del hombre; la hace no solamente el rico que quiere aumentar su riqueza sino también el pobre, que necesita poner remedio a su pobreza. La guerra en su origen, constituye, en otros términos, el medio del connubium y del commercium. Ahora, para excluirla el connubium 
Pero pareciera que el asunto cuenta con alguna arista más. Así, con carácter general podríamos señalar que existe una prohibición de la fuerza tanto en el orden civil como en el orden penal. En el orden penal se sanciona el uso de la fuerza mediante la consagración de múltiples tipos delictivos que, claramente, están orientados a evitar esa conducta en nuestra sociedad. También es importante recordar que la fuerza es un vicio de la voluntad consagrado en el 1456 del Código Civil y todo acto realizado bajo aquellas condiciones, y no el mero temor reverencial, es susceptible de ser anulable.

Sea como fuere, en lo que parece haber concordancia en la doctrina es que la solución del conflicto debe llevarse a cabo por medios no violentos fomentados por el uso de la venganza como móvil de las acciones ejecutadas ${ }^{31}$.

Ese uso de la fuerza es un concepto relativamente difuso puesto que puede ser violencia puramente física, o también una coacción o amenaza seria y suficiente como para limitar la autodeterminación del sujeto pasivo. Además, puede usarse por quien quiere ser beneficiado directamente o, también, por un tercero, como en el caso del soldado en la guerra ${ }^{32}$.

El centro de esta problemática está marcado por la necesidad de, existiendo un conflicto, acudir a un tercero para que sea él quien despojado de otros intereses lo solucione. De lo contrario, una parte impondrá su decisión a la otra tomándose la justicia por su propia mano y, si bien es cierto que no determina automáticamente el uso de la fuerza física, lo más probable es que esto también ocurra. Por este motivo, se abre una puerta a pensar en que la autotutela, no siendo exclusivamente el uso de

y del commercium deben ser de otro modo garantizados. Los hombres no roban ni mujeres ni bueyes por robar, sino para formar su familia y su casa. En lugar de la guerra, debe pues, permitirse otro medio de connubium y de commercium para que su prohibición sea realmente eficaz" Para concluir, en este escenario: "La primer función de la compra es precisamente la de subrogado del hurto. Contrato y delito aparecen, por tanto, como la cara y la cruz de la misma moneda. Igualmente son complementarios el derecho penal y el derecho civil. Mientras el primero expulsa la guerra el segundo establece las condiciones necesarias para que los hombres puedan vivir sin hacerla. La complementariedad de lo civil a lo penal constituye uno de los fundamentos del derecho".

31 Sintética y diáfanamente lo explica Nieva: "las disputas por todo lo que en aquel momento se consideraba un bien material -lo que podía incluir también a las personas- se resolvieran por medios no violentos, probablemente para evitar guerras que, finalmente, provocaban inestabilidad y una gran vulnerabilidad frente a los ataques de grupos vecinos provocados probablemente, en la mayoría de los casos, por disputas basadas en la búsqueda de alimentos o en el predominio del linaje. Aunque no siempre tuvieran esos orígenes más comunes, los mismo pueden ser los mayoritarios, al estar basados en una máxima biológica universal suficientemente contrastada: la selección natural, que solamente los seres humanos hemos conseguido poner en cuestión" (Nieva Fenoll, Jordi (2014) Derecho procesal I. Introducción. Madrid: Marcial Pons, 310 pp., p. 10). 
la fuerza ${ }^{33}$, está prohibida porque genera injusticia material la posición de sometimiento de una parte sobre la otra ${ }^{34}$. Sería una característica destacable, más allá de la violencia ${ }^{35}$.

Pero esta prohibición general no tiene sentido sino hasta su comprobación judicial. Así, hablaremos de autodefensa homologada en aquellas situaciones en que, finalmente, un tercero imparcial comprueba que, efectivamente, se cumplieron con los requisitos excepcionales que la ley señala para tolerar el uso de la justicia por la propia mano ${ }^{36}$.

Sin duda, la mala fama de la autotutela viene dada por su perspectiva penal $^{37}$. Desde el periodo de venganza o justicia privada ${ }^{38}$ está marcada por ser un derecho o un deber, incluso, de combatir hasta la muerte para reparar un hecho de sangre u otro tipo de agresión de entidad importante. Pese a que posteriormente, se va a ir pensando en la asunción de criterios de responsabilidad objetiva como medio de renunciar a la venganza, la muerte y medios análogos de violencia caracterizan la solución del conflicto. Por su parte, tampoco mejora sustancialmente este panorama durante la época de venganza o justicia pública puesto que la ley del ta-

33 Así, en el caso español Gimeno SENDRA destaca la realización arbitraria del propio derecho (art. $455 \mathrm{CP}$ ) o el delito de coacciones (art. $172 \mathrm{CP}$ ), que no necesariamente implican el uso de la fuerza física. Pero sí, genera el peligro que una organización estatal débil se vea comprometida por la injusticia. Véase, Gimeno Sendra, Vicente (2014) Introducción al Derecho Procesal. Madrid: Colex, 357 pp., p. 18.

34 Esta idea proviene de la lectura comprensiva de algunas formas de describir este fenómeno. Entre ellos, por ejemplo Gómez Colomer quien señala: "Esta forma de resolver los conflictos intersubjetivos de intereses jurídicos se da cuando una parte impone su solución a la otra, generalmente mediante el uso de la fuerza. Como es fácilmente imaginable, no solo no suele ser una manera justa de resolver problemas, sino que más bien se está ante una ocasión magnífica de tomarse la justicia por propia mano. Por ello y como regla general, la autotuela, también llamada autodefensa, debe estar prohibida por el ordenamiento jurídico" (Gómez Colomer, Juan Luis (2014) "Medios de solución de los conflictos colectivos". En Montero Aroca et al.: Derecho Jurisdiccional I. Valencia: Tirant lo Blanch, 355 pp., p. 38).

35 Es más, pudiera ser que cuanto más primitivo es el avance de la sociedad, destaquemos otros conceptos de imposición autoritaria de una solución como una mejor condición social que permite la imposición de una solución por la ostentación de una situación hegemónica. En este sentido, Castillejo Manzanares, Raquel (2014) Del poder de disposición de las partes sobre el proceso civil y sobre sus pretensiones. Madrid: La Ley, 324 pp., p. 66.

36 Véase, Maturana Miquel, Cristian y López Montero, Raúl (2010) Derecho Procesal Penal. Santiago: Abeledo Perrot-LegalPublishing, 513 pp., p. 9.

37 Probablemente, pudiéramos encontrar un antecedente que, despojado de consideraciones penales, le haya generado ese componente negativo a esta institución. En efecto, señalaba Alcalá Zamora: "La autodefensa, que combina la parcialidad y el egoísmo, aparece desde el primer momento como una solución deficiente y peligrosa en grado superlativo, y de ahí que, explícita o implícitamente los ordenamientos jurídicos de los Estados merecedores de este nombre la prohiban como regla, aunque la consientan en situaciones excepcionales, y aun en ellas suele ser necesario un proceso ulterior, precisamente para declarar la licitud de la misma en el caso concreto" (Alcalá Zamora (2000) 13).

38 Seguimos, en este punto, las etapas propuestas por Politoff, Sergio; Matus, Jean Pierre y Ramírez, Ma Cecilia (2008) Lecciones de Derecho Penal Chileno. Santiago: Editorial Jurídica de Chile, 613 pp., p. 20 y ss. 
lión, y en clave de sucesos violentos, no parece una mejoría tan relevante: el hecho de "pagar" ojo por ojo, o diente por diente. Pese a que hay un avance innegable, observamos que el centro de la regulación, continúa girando en torno a hechos de violencia, que se combaten con la misma violencia. Incluso el periodo humanitario o la codificación liberal, no se avizora un mejor panorama puesto que siempre asociamos Derecho penal a los hechos más graves que golpean a nuestra sociedad.

En otro orden de ideas, se ha descrito el ejercicio legítimo de un derecho como una forma de evitar la antijuricidad de un hecho presumiblemente punible ${ }^{39}$. Ese ejercicio legítimo puede conducir, también, a ejercer la justicia por la propia mano y como regla general, siempre que implique violencia será un hecho prohibido. Se suelen mencionar como ejemplos de aquello el art. 494 No 20 y 494 No 16 del Código Penal y, de manera muy sencilla entendemos que no se puede obligar a alguien a realizar aquello que no quiere aunque sea debido por la víctima. En el caso que no se emplee violencia si se trata solo de ejercitar un derecho que otro impide ejercer, no habrá delito ${ }^{40}$. Pero cuando se trata de "mejorar" un derecho, si habrá delito ${ }^{41}$.

Esta prohibición del uso de la fuerza, que en definitiva, permea el inconsciente de los individuos como si de un axioma se tratara, se complementa con el principio de exclusividad de los tribunales, como entes que ejercen jurisdicción. En este caso, la Carta Fundamental señala que le corresponde a los tribunales la resolución y ejecución en las causas civiles y penales.

De este modo, ambos factores - prohibición penal y principio de exclusividad-convergen para generar una idea que nos cuesta superar desde el punto de vista del Derecho procesal, como derecho público: la autotutela es una forma legítima de solución del conflicto.

A mayor abundamiento, se han descrito formas civiles de autotutela que despojadas de violencia propiamente tal, contribuyen a resoluciones injustas del conflicto porque una de las partes impone su voluntad, probablemente, por una mejor posición, normalmente económica o negocial: la detención privada del deudor sospechoso en fuga; la patria potestad, las instituciones tutelares o aquellas en que subsista una autoridad marital;

\footnotetext{
39 Seguiremos, en este extremo, lo propuesto por Etcheberry, Alfredo (1999) Derecho Penal. Parte General. Santiago: Editorial Jurídica de Chile, 361 pp., pp. 244-247.

40 ETCHEBERry (1999) 245.

41 El claro ejemplo que propone ETCHeberry es el del acreedor que sustrae dinero del bolsillo del deudor para hacerse el pago: "La Ley, frente al incumplimiento del deudor, señala las vías de reparación: acciones judiciales. No autoriza, explícita implícita mente, al acreedor para sustraer directamente el dinero del deudor. Habría que sancionar a dicho acreedor, autor de hurto, aunque tal conclusión choca profundamente con la paradójica circunstancia de que si emplea violencia en vez de clandestinidad, su acción resulta menos grave, pues en vez de ser considerada robo, es una mera falta" (ETCHEBERRY (1999) 246).
} 
el pacto comisorio respecto de bienes dados en prenda o la ejecución por obra del acreedor en créditos pignoraticios ${ }^{42}$.

Por todo lo descrito y con mayor razón al encontrar motivos en la legislación civil que no implican violencia física, existe una tendencia a pensar que la autotutela es inmoral en tanto que no permite una igualdad de partes y puede suponer imponer la autoridad por miedo (por ejemplo en las relaciones tutelares) o por aprovechamiento de una situación privilegiada al exigirse una garantía desproporcionada a propósito del pacto comisorio $^{43}$.

\section{3) Autotutela Permitida: EXCEPCiOnes a LA PROHibición DE AUTOTUTELA}

Como hemos venido relatando, existe una prohibición general de autotutela y, por otra parte, una serie de excepciones reguladas específicamente en el ordenamiento jurídico. Así, entonces, podemos constatar que en ocasiones se puede hacer justicia por la propia mano, pese a que exista violencia porque existe alguna razón que justifica tal actuar.

El caso más claro de esta manifestación es la institución penal conocida como legítima defensa. Recogida en el art. 10 del Código Penal en sus numerales 4, 5 y 6 permite, al eximir de responsabilidad penal, que las personas que sufren una agresión ilegítima $-\mathrm{y}$ siempre que no medie provocación- puedan defenderse, directamente, de forma racional para conseguir repeler aquella agresión. Por tanto, se permite la justicia por la propia mano, probablemente, justificado por la necesidad de actuación inmediata para evitar un mal mayor que, de ninguna manera, pudiera esperar la tramitación ante un Tribunal de Justicia, ni tan siquiera en forma automática. En esta misma línea, podríamos señalar también el estado de necesidad (art. 10 No 7 CP) y la obediencia debida o cumplimiento de un deber (art. 10 No $10 \mathrm{CP}$ ).

Además existen otros ejemplos, que nos parecen tan o más paradigmáticos. En primer lugar, la posibilidad de perseguir abejas en fundo ajeno contemplada en el art. 620 del Código Civil; Más claro, si cabe, la posibilidad de pedir el corte de ramas y, directamente, cortar las raíces del árbol del vecino cuando ingresa al dominio propio. En este caso, se ve muy clara la posibilidad de uso de la fuerza (fuerza física necesaria) para sin necesidad de pedir permiso- "defender" la propiedad particular de las perturbaciones externas.

Alcalá Zamora (2000) 39.

Wegmann Stockebrand, Adolfo (2009) “Algunas consideraciones sobre la prohibición del pacto comisorio y el pacto marciano". Revista Chilena de Derecho Privado, No 13, pp. 95122. 
A su vez, hallamos otros ejemplos civiles en el derecho de retención respecto del arrendatario contemplado en el art. 1937 CC, o del mandatario regulado en el art. 2162 CC, el del comodatario (arts. 2192 y 2193 CC), el del depositario (arts. 2234 y 2235 CC) y del acreedor prendario (art. 2.401 CC).

Se suelen nombrar, también como ejemplos de esta figura el cierre temporal de la empresa (lock out) y el derecho a huelga (arts. 369 y ss. del Código del Trabajo) en que una de las partes ejerce presión negociadora mediante una actitud perjudicial para la otra parte.

Y, finalmente, como resquicio más clásico sobrevive entre nosotros la institución de la guerra. Reglada y limitada, pero guerra al fin y al cabo, la legislación internacional prevé la posibilidad de acudir a la guerra preventiva como forma de autodefensa de los intereses legítimos de una nación ${ }^{44}$.

Por otra parte, se han querido ver ejemplos no tan clásicos como la facultad de corrección de los hijos (art. 234 CC); la retención de equipajes ${ }^{45}$; y la reposesión de bienes muebles, paradigmáticamente automóviles, en el caso anglosajón ${ }^{46}$.

\section{4) REPOSESIÓN: UNA PROPUESTA DE AUTOTUTELA}

Entre nosotros existe una prohibición autotutelar en aquellos supuestos en que el acreedor pretende satisfacer su crédito aprehendiendo algún bien del deudor como medio de hacer frente al pago de la obligación. Sin embargo esta situación se encuentra regulada en el Derecho comparado, al menos en Alemania ${ }^{47}$, Reino Unido ${ }^{48}$ y EE.UU.

Resulta muy interesante, observar las reflexiones de Caro Garzón, Octavio Augusto (2006)

"La doctrina Bush de la guerra preventiva ¿evolución del ius ad bellum o vuelta al medioevo?". Revista Facultad de Derecho y Ciencias Politicas, Vol. 35, No 105, pp. 399-429.

45 Norma que ya se contemplaba en el art. 175 de la Costumbre de París y que hoy se encuentra vigente, por ejemplo, en el art. 870 del Código de Comercio de Guatemala.

46 Mentschikof, Soia (1973) "Paceful Repossession under the Uniform Commercial Code: A constitutional and economic analysis“. William \& Mary Law Review, Vol. 14, No 4, pp. 767-786.

47 En relación a los bienes muebles dejados en la vivienda arrendada por el arrendatario en mora, Bürgerliches Gesetzbuch, $\$ \$ 562 \mathrm{~b}$.

48 Un buen ejemplo de análisis de los requisitos de la más paradigmática repossession escocesa, puede consultarse en el fallo de la Corte Suprema de Escocia de 24 de noviembre de 2014 (Disponible en: https:/www.supremecourt.uk/cases/docs/uksc-2009-0228-judgment.pdf). Además, en términos generales es imprescindible destacar que la Consumer Credit Act 1974, с 39 (Eng) en su art. 90 señala: "Retaking of protected hire-purchase etc. Godos: (1) At any time when- (a) the debtor is in breach of a regulated hire-purchase or a regulated conditional sale agreement relating to goods, and (b)the debtor has paid to the creditor onethird or more of the total price of the goods, and (c)the property in the goods remains in the creditor, the creditor is not entitled to recover possession of the goods from the debtor 
En lo específico, y atendido que cada uno de los mentados países tiene sus particularidades propias, nos vamos a fijar en lo que acaece en EE.UU. Si bien es cierto que existen características individuales mínimas marcadas por Estado, no es menos cierto que la norma general inspiradora de las demás, se encuentra recogida en el art. 9 del Uniform Commercial Code ${ }^{49}$.

El Uniform Commercial Code ("UCC") es un modelo de código de Derecho comercial. Se trata de un proyecto conjunto de la Conferencia Nacional de Comisionados en Derecho Estatal Uniforme ("NCCUSL", por sus siglas en inglés) y el Instituto de Derecho (norte) Americano (ALI). El UCC no es una ley, sino una propuesta realizada por expertos en relación a la ley que deberían adoptar los Estados que conforman la unión. Cada Estado aprueba, dentro de sus atribuciones, su normativa comercial, que, generalmente consiste en una copia casi literal del UCC. Cabe destacar que cada nueva edición de UCC, es acompañada por unos comentarios oficiales, donde prestigiosos juristas establecen su opinión acerca del significado y aplicación de dicha normativa modelo.

La repossession es una institución por la que un acreedor, generalmente un banco o una automotora, toma físicamente un bien que había sido adquirido, o sobre el que recaía un leasing o arrendamiento común, con el objeto de venderlo y pagarse con el producto, del mismo modo que si se tratara de una venta al martillo, o en pública subasta, pero sin la necesidad pasar por un Tribunal de Justicia, ni tramitar un proceso de cognición previo.

En otras palabras, se trata de un mecanismo por el que un acreedor garantizado incorpora para su patrimonio el bien objeto de dicha garantía, sin necesidad de acudir a un proceso ${ }^{50}$. Se trataría de una fórmula de autotutela o autodefensa del acreedor que observando que deja de percibir los pagos asociados a un crédito privilegiado evita la vía jurisdiccional aprehendiendo el bien como forma de satisfacer el crédito o la parte que el bien pueda cubrir en una venta. El Art. 9 trata profusamente los derechos de garantía sobre bienes muebles. Para la UCC el concepto de bien mueble ("goods") se consigue, con las habituales excepciones normativas, por mera oposición al concepto de bien inmueble ${ }^{51}$.

except on an order of the court". Es decir, que en un contrato de alquiler con opción de compra, si el deudor y el acreedor lo acuerdan, y siempre que la deuda sea mayor a dos tercios del precio, el acreedor puede ejercer la institución de la repossession.

49 En específico la norma tiene su fundamento en el $\$ 9-609$ que con carácter general asegura el derecho de la parte a tomar posesión tras la cesación de pagos y la letra b.2 del mismo parágrafo establece que aquel derecho procede sin necesidad de proceso judicial siempre que no exista una alteración de la paz (without breach of the peace), U.C.C. 9-609 (2010).

50 U.C.C. $\$ 9-609(2010)$.

$51 \quad$ U.C.C. $\$ 2-103(\mathrm{k})(2010)$. 
De este modo, una vez que el bien se integra en la esfera del acreedor este lo vende por sí mismo o por terceros y con aquel producto paga el crédito. Si no se alcanzase a cubrir la totalidad, podrá demandarse el resto en la vía jurisdiccional ordinaria y si, por otra parte, se hubiera conseguido un valor más alto al de la venta, será el deudor quien tenga derecho a recibir la diferencia a su favor ${ }^{52}$.

Para que este mecanismo sea lícito ${ }^{53}$ y posible se deben considerar varias condicionantes. En primer lugar, se trata de un acuerdo de voluntades por el que el acreedor entrega al deudor un bien de valor. El deudor debe tener derecho suficiente para otorgar la garantía que se dirá y, adicionalmente, el deudor debe otorgar un contrato (sentido laxo) en el que se describa suficientemente el bien dado como garantía ${ }^{54}$. Típicamente, en este acuerdo se especifican tanto el valor de la deuda, como de cada uno de los montos unitarios a cancelar. Por otra parte, se especifica la garantía que, básicamente consiste en que el acreedor del crédito podrá tomar el bien mueble desde el lugar donde se encuentre para recuperarlo, y en su caso, venderlo y liquidar la deuda correspondiente. Esta figura ha conocido un uso intensivo en el caso de los vehículos automotores.

A su vez, pensando en cómo el mecanismo no guarda notas de antijuricidad, debe existir una mora del deudor que genera el interés del acreedor por acelerar los trámites para satisfacer el crédito. El acuerdo suscrito debe señalar el plazo por el que se considera que la mora produce la legitimación para que el acreedor retire la especie.

Así pues, deben concurrir estos dos requisitos para que se produzca la aprehensión del bien. Por una parte debe existir acuerdo y, por la otra, el deudor debe encontrarse en mora. Lo más habitual, tal y como sucede en los procedimientos ejecutivos, es que ante este escenario el acreedor requiera de pago al deudor y no pagando este, el acreedor, entre dirigirse a los tribunales de justicia o resolver por la vía de la autotutela, se decida por la repossession del bien cuyo objeto será satisfacer el crédito.

Sin embargo, una vez concurridos los requisitos y llegado el momento material de la ejecución del acuerdo, vale decir la aprehensión material

52 U.C.C. $\$ 9-615(2010)$

53 Efectivamente, entre nosotros puede llamar poderosamente la atención esta figura por su marcado carácter autodefensivo. Sin embargo, en la cultura anglosajona la autodefensa no guarda una connotación negativa justificada, en muchas ocasiones por motivos históricos. Así, por ejemplo, en State v. Indrisano, 29 Conn. App. 283, 286, 613 A.2d 1375 (1992):

"Private self-help remedies extend as far back as ancient Greece, where those entitled to seize chattels from a debtor were not prohibited from breaching the peace or physically injuring the debtor in the course of repossession (...) Early Roman law permitted similar self-help remedies, including the right to seize the person of a debtor, without court action, after a default in payment (...) Later, the right to repossess goods was recognized in the common law of England". 
del bien por el acreedor, debe respetarse una circunstancia que es la ausencia de la breach of the peace, es decir, la ausencia de violencia o alteración del orden que esta circunstancia pudiera acarrear. Así, no se pueden romper cerraduras $\mathrm{u}$ otros dispositivos de seguridad para obtener acceso a un lugar, como tampoco se puede sacar por la fuerza al conductor para desposeerlo del vehículo ${ }^{55}$.

El concepto de breach of peace no ha sido definido, de manera consciente, por sus redactores, dejando su interpretación al arbitrio de los tribunales encargados de aplicar la norma ${ }^{56}$. Judicialmente, se ha definido el breach of peace de manera genérica como "una alteración del orden público causada por un acto de violencia o por un acto que previsiblemente produzca violencia o por el que se cause consternación y alarma, o perturbe la paz y tranquilidad de la comunidad" 57 , sin embargo es mucha la jurisprudencia que, siguiendo a los comentaristas oficiales reconocen la falta de existencia de una definición concreta ${ }^{58}$.

Por lo tanto, es aconsejable que el acreedor garantizado paralice la ejecución material de la autotutela en cuanto percibe la mínima resistencia del deudor o de terceros. Al punto que, jurisprudencialmente, se ha llegado a establecer la mera protesta verbal constituye uno de los supuestos que configuran el breach of peace ${ }^{59}$. Actos tales como la mera presencia policial sin mandato judicial ${ }^{60}$; la protesta por un apoderado del deudor; cortar una cadena que cerraba una puerta; o romper ventanas o puertas de garaje han sido considerados breaches of peace. En cambio, actuar con

55 Ver, entre otros, Martin v. Dorn Equip. Co. 821 P.2d 1025, 1026-28 (Mont. 1991) (cortes de cadenas); Davenport v. Chrysler Credit Corp., 818 SW.2d 23, 26, 29-30 (Tenn. Ct. App. 1991) (el coche estaba atado con cadenas a la pared del garaje, dicha rotura fue considerada breach of peace).

56 De esta manera, la sección 3 de los Official Comments to Section 9-609 establecen que "this section does not define or explain the conduct that will constitute a breach of peace, leaving that matter for continuing development by the courts" U.C.C. $59-609 \mathrm{cmt} \mathrm{3,} 2005$.

57 Así, en People v. Most, 171 N.Y. 423, 64 N.E. 175 (1902), a breach of peace is " .[...] a disturbance of public order by an act of violence, or by any act likely to produce violence, or which, by causing consternation and alarm, disturbs the peace and quiet of the community".

58 Así, Ryan McRobert en Defining Breach of the Peace in Self-Help Respossesions "the lack of a clear definition for "breach of peace" in the self-help repossession context", citando el caso Chapa v. Traciers \& Associates, 267 S.W. $3 d 386$ (Texas Ct. App. 2008). Mc Robert, Ryan (2012) "Defining Breach of the Peace in Self Help Repossessions", 87 Washington Law Review, 569.

59 Así entre otras en Marcus v. McCollum, 394 F.3d 813, 820 (10th Cir. 2004) (la mera oposición verbal disturba la paz). Aunque ad contrarium en otras ocasiones, decir "usted no se lleva este auto" no es considerado breach of peace ya que dicha afirmación del deudor per se no incita necesariamente a una situación violenta, Chrysler Credit Corp. v. Koontz, 661 N.E.2d 1171, 117374 (111. Ct. App. 1996).

60 Stone Machinery Co. v. Kessler. 1 Wash. App. 750, 757, 463 P.2d 651, 655 (1970). 
engaño; la entrada en propiedad privada sin vallar; o sacar un auto de un garaje abierto, no han sido considerados breach of peace $e^{61}$.

Este límite provoca el mantenimiento de la convivencia social y evita una confrontación violenta entre acreedor y deudor. Con ello, no debemos perder de vista el hecho que, finalmente, el acreedor impone su voluntad al deudor y evita un proceso judicial. En realidad, la maniobra de recuperación de un automóvil (por ser el caso más emblemático) se realiza de forma tan rápida que, muchas veces, no genera violencia debido a que el deudor, ni tan siquiera avizora el fenómeno. Ahora bien, si el deudor se opusiera, esta figura cesa y el acreedor debe irse pacíficamente del lugar quedando expedita la vía judicial ordinaria y la acción correspondiente.

Adicionalmente, se producen otra serie de circunstancias que rodean a esta institución y que la hacen interesante para su evaluación entre nosotros. Habitualmente, este tipo de acciones se realizan de noche para evitar la alteración del orden público ya que si el deudor está descansando, no se puede conformar el breach of the peace ${ }^{62}$. Ello podría generar el problema de las pertenencias que se encuentren dentro del automóvil al momento de su retiro y es por ello, que si el deudor está presente, se le debe permitir que pueda extraer todas las pertenencias ${ }^{63}$. En todo caso, se le deberá dar aquella posibilidad una vez el bien haya sido ingresado a la esfera del acreedor. Es decir, el acuerdo solamente permite recobrar un bien y no aquello que contenga.

Por otra parte, es importante señalar que no se puede restablecer el orden, o precaver la alteración del mismo, mediante el aviso a la policía ${ }^{64}$. El hecho que la policía se persone, significa, que nos encontramos ante un supuesto de violencia. El aviso a la policía, destinado a evitar que el asunto pudiera parecer un tipo penal debe realizarse después que el acreedor tiene en su poder la cosa ${ }^{65}$.

61 Entre otros, en Martin v. Dorn Equip. Co. 821 P.2d 1025, 1026-28 (Mont. 1991) (corte de cadenas); Williamson v. Fowler Toyota, Inc., 956 P.2d 858, 859, 862 (Okla. 1998) (cadenas alrrededor del porton del jardín); Davenport v. Chrysler Credit Corp., 818 SW.2d 23, 26, 2930 (Tenn. Ct. App. 1991) (cadenas que sujetan al auto a la pared). Pero, 128. See, e.g., Butler v. Ford Motor Credit Co., 829 F.2d 568, 570 (5th Cir. 1987) (la entrada en propiedad privada para llevarse el auto sin más acción u omisión no constituye breach of peace), en Koontz la corte llega a afirmar que [haberle dado carta de breach of peace a la mera protesta verbal] hubiera invitado a la situación ridícula (énfasis añadido) por la que un deudor puede evitar el pago de lo debido simplemente chillando.

62 Así, Ragde v. Peoples Bank, 53 Wash. App. 173, 176-77, 767 P.2d 949, 951 (1989) (llevarse un auto de una propiedad privada a las 5 de la madrugada no es breach of peace).

63 Así, Mc Robert, id. Citando el caso Williams v. Ford Motor Credit Co., 674 F.2d 717, 720 (8th Cir. 1982), en el que el tribunal considera que no hubo breach of peace, cuando el deudor solicitó sacar sus enseres y el acreedor se lo permitió, no yendo más allá en su protesta, en el momento de llevarse el vehículo.

64 McClellan v. Gaston, 51 P. 1062, 1064 (Wash. 1898).

65 Debido a que la numerosa jurisprudencia que sigue a Stone Machinery Co. v. Kessler. 1 Wash. App. 750, 757, 463 P.2d 651, 655 (1970), donde la mera presencia policial fue considerara 
El siguiente momento importante es la realización del bien. El acreedor debe informar al deudor de cuándo y dónde se va a proceder a la venta del automóvil con el objeto que este pueda concurrir a la misma y recobrar el bien pagando el precio. En último lugar, el acreedor debe informar de la deuda que pudiera existir, una vez se ha realizado la venta $y$ adicionando los costos que implicó el proceso. En caso que la venta no hubiera cubierto la totalidad del crédito, subsistirá una deuda que permitirá acudir a la vía judicial ${ }^{66}$ y, por el contrario, si se hubiera superado el valor del mismo, el deudor tendrá derecho a que se le pague la diferencia a su favor que corresponda.

\section{5) Autotutela del ACREEDOR EN NUESTRO ORDENAMIENTO JURÍDICO}

El tema de la autotutela del crédito no es ajeno a nuestro entorno. Sin embargo, el enfoque tradicional entre nosotros ha sido prohibirla porque no se concibe que no pueda mediar violencia. La presentación que hemos realizado acerca de la autotutela implica el uso de la fuerza y el sometimiento de una voluntad a la otra parte. Por otra parte, sin mediar violencia y aprovechando una posición de negociación privilegiada se prohíbe el pacto comisorio en el art. 2397 del Código Civil ${ }^{67}$.

La figura más cercana a la repossession anteriormente descrita se encuentra recogida en el art. 494 del Código Penal que regula las faltas. Específicamente, el numeral 20 recoge el hecho que alguien se apodere de una cosa que le pertenece a su deudor para liquidar el crédito existente entre ellos ${ }^{68}$. Precisamente, con algunos matices, guarda una absoluta similitud con aquella institución de derecho comparado que, al contrario, permite aquella conducta.

Este tipo de autotutela prohibida por nuestro ordenamiento tiene su antecedente más cercano en el art. 421 del Código Penal español de 1850 que condenaba como delito la realización arbitraria del propio dere-

un breach of peace, la práxis aconseja avisar con posterioridad a la autoridad en el caso de una reposesión con éxito a los efectos de comunicación posesoria del vehículo.

Sin embargo, en Estados como Minnesota no se podrá perseguir la cantidad impaga judicialmente cuando el monto total (original) del crédito haya sido de 6,900 US\$ o menos Minn. Stat. Ann. \$325G.22 (2015).

67 Por sus similitudes con la garantía contractual estipulada en el contrato que sirve de fundamento a la institución anglosajona de la repossession, parece muy interesante revisar algunas consideraciones dogmáticas realizadas en nuestro entorno. Al respecto, puede consultarse, Wegmann Stockebrand (2009) 95-122.

68 Literalmente, el art. 494.20 CP señala: "El que con violencia se apoderare de una cosa perteneciente a su deudor para hacerse pago con ella". 
cho $^{69}$. Actualmente, este delito todavía se encuentra vigente en el art. 455 del Código Penal español al señalar que "El que, para realizar un derecho propio, actuando fuera de las vias legales, empleare violencia, intimidación o fuerza en las cosas, será castigado con la pena de multa de seis a doce meses". De una simple lectura, podemos observar que existe un énfasis en prohibir la autotutela concebida como un conjunto de actos violentos y, por lo señalado, la lógica impone desterrar este método de la resolución del conflicto como válido.

En nuestro ordenamiento no es un tópico desconocido y son varias las hipótesis que se plantean, todas lejos de la autotutela lícita u homologada que observamos para la repossession. Así, se han expuesto algunas consideraciones doctrinales que, en rigor, a lo que apuntan es a tratar de delimitar la figura correctamente y separarla de otras afines. Pero en realidad, no se ha construido una tesis para plantear una forma de agilizar la solución rápida del conflicto.

Lo que caracteriza a esta conducta es el hecho de tratar de ejercer la justicia por cuenta propia y es, precisamente aquello, lo que se prohíbe. A su vez, es importante destacar, como también lo ha hecho la doctrina ${ }^{70}$, que la conducta específicamente proscrita es aquella que conlleva el uso de la violencia para lograr el objetivo que, no es otro que satisfacer un crédito o parte de este.

Resulta curioso, entonces, porque algún sector doctrinal al analizar con detenimiento a qué nos conduce la autotutela, independientemente del uso de la violencia, señala que indefectiblemente nos conduce a la comisión de un ilícito. Imposibilitando, en todo caso, la realización de justicia por la propia mano ${ }^{71}$, porque hasta en el menos grave de los supuestos, existe una vulneración del ordenamiento jurídico: razonablemente esta conclusión viene dada porque es fácilmente entendible que no está permitido apropiarse de lo ajeno, aun y cuando no exista violencia ${ }^{72}$.

69 Mañalich Raffo, Juan Pablo (2009) Autotutela del accedor y protección penal del deudor. La realización arbitraria del propio derecho frente a los delitos contra la libertad, la propiedad y el patrimonio. Santiago: Ediciones Jurídicas de Santiago, 134 pp., p. 14.

70 En efecto, en la figura española asimilable al escenario chileno y desde hace tiempo se ha señalado como característica principal la existencia de violencia. Así, Muñoz Conde, Francisco (2001) Derecho Penal. Parte Especial. Valencia: Tirant lo Blanch, 1039 pp., p. 905.

71 Es Cury quien señala que no existe un derecho a hacer justicia por la propia mano (CuRY, Enrique (2005) Derecho Penal Parte General, Tomo I. Santiago: Editorial Jurídica de Chile, 812 pp., p. 346).

72 En esta misma lógica Etcheberry (1999) 246, al analizar este tipo explica que puede ser hurto o autotutela ilícita. A su vez, describe, excelentemente la paradoja que es menos gravoso para el sujeto activo del ilícito realizarlo con violencia, puesto que de lo contrario, deberá asumir una pena mayor, la asociada al robo, en vez de una falta. Sin embargo, en este extremo es interesante consultar otro tipo de figuras civiles que no llevan necesariamente a la comisión de un delito como pueden ser la posesión viciosa o clandestina. Es más, incluso sin tratarse de un tipo de posesión inútil, el poseedor puede enajenar el bien y el tercero adquirente de buena fe se encontrará protegido por el ordenamiento jurídico devolviendo el objeto al tráfico jurídico. 
Ahora bien, sabemos por la experiencia forense que incluso hay supuestos en que alguien consigue el dominio de un bien inmueble basado en una falsificación registral.

Entre la doctrina nacional hay varias posiciones que ayudan a dar cuenta del objetivo de determinar cuál es el contenido de aquella prohibición y, de este modo, ir adelantando si es que acaso la repossession pudiera significar un ilícito en nuestro ordenamiento jurídico ${ }^{73}$.

Este tipo de fenómeno ha sido estudiado desde el concepto de antijuricidad. La doctrina penal señala sin titubeos que el ejercicio de un derecho legítimo justifica la acción del individuo ${ }^{74}$. De este modo, quien actúa legítimamente aprehendiendo un bien mueble con el objetivo de satisfacer un crédito no debiera realizar una conducta antijurídica, si no media violencia. El elemento, entonces, que convierte a esta institución en algo prohibido entre nosotros es el empleo de la violencia. De tal suerte que la ausencia de violencia solamente conduciría a un eventual ilícito civil, y en nuestra opinión siempre que aquello derivara de una actividad contractual, no daría derecho a reparación indemnizatoria ${ }^{75}$.

Otra forma de describir esta situación es hacerlo enfatizando que debe tratarse de un derecho legítimo que, por lo tanto, evita el exceso o abuso en el ejercicio del mismo y ello conduce a soslayar el ejercicio arbitrario del propio derecho ${ }^{76}$. Pero esta forma de definirlo no cuenta con el componente "violencia" que pareciera ser, en definitiva, el elemento que justifica la prohibición de la conducta.

Como bien ha definido la doctrina, pudiera ser un instituto que no deja de ser relevante. En principio, parece absurdo señalar que no guarda antijuricidad la conducta que ejerce un legítimo derecho y, ello ha de ser así, hasta el momento en que la forma o manera de ejercerlo se convierte

73 El profesor MañALICH (1999) 25-32 ha recogido el estado del arte que pretendemos revisar sucintamente de inmediato.

$74 \quad$ Cury (2005) 381.

75 En este mismo sentido, Cury (2005) 381 aclara respecto del contenido del art. 494 No 20, que en realidad se corresponde con la acción que estamos describiendo para la repossession, que "Si, por la inversa, el hecho realizado se adecua a la descripción de un tipo que no incluye la violencia, una interpretación a contrario de los referidos preceptos y del art. 471, No 1 del C.P., conduce a la conclusión de que la conducta es atípica, y procederán las reparaciones civiles". Conviene, en este momento precisar en este extremo que la figura de la repossession descrita, si bien pudiera guardar notas que la asemejen al pacto comisorio, también destacaría por otras que lo alejan de aquel. Así, en rigor, en la repossession no hay una adjudicación directa del bien, sino una organización privada para fomentar la venta en subasta y, por otra parte, basta del acuerdo de voluntades para materializarlo, sin otro tipo de consideraciones como la existencia de una deuda o el registro a efectos de oponibilidad.

76 Politoff (2004) 237. Por otra parte, puede resultar interesante consultar esa institución española que desde antiguo ha sido analizada, pero que no termina de conformar el supuesto que estamos desarrollando. Por todos, véase el clásico estudio BAjo Fernández, Miguel (1976) La realización arbitraria del propio derecho. Madrid: Ed. Civitas, 89 pp. 
en una cuestión que pueda generar responsabilidad penal ${ }^{77}$. Efectivamente, lo más relevante a la hora de ejercer un derecho es ejecutar su contenido dentro de los límites que él mismo señale. A mayor abundamiento, hay que considerar que no siempre la forma abusiva constituye un tipo penal ${ }^{78}$. Entonces, siguiendo lo señalado por GARrido MontT, existe la posibilidad de hacer justicia por la propia mano, siempre que no se conformen señales de violencia o coacción, puesto que es aquello, precisamente, lo que se protege por el ordenamiento jurídico ${ }^{79}$.

A su vez, en forma más específica la doctrina ha destacado algunas ideas dignas de traer a colación. En primer lugar, se ha sostenido que en rigor lo más oportuno sería derogar la norma contenida en el art. 494.20 $\mathrm{CP}$, puesto que el apoderamiento violento siempre debiera conducir al tipo de robo ${ }^{80}$. Para otros autores ${ }^{81}$, significaría una figura privilegiada frente al hurto y no estaríamos frente al robo puesto que se entendería que el uso de la violencia no implicaría una entidad mayor a lesiones leves. Y, finalmente, la doctrina también ha destacado que en rigor pudiera tratarse de una hipótesis de contenido específico a lo señalado en el art. $494.16 \mathrm{CP}^{82}$.

En la especificidad del análisis, sin embargo, llama poderosamente la atención como para GARRIDo MontT siempre se comete un ilícito penal, independientemente de la violencia. Así, en un diálogo con ETCHEVERrY nos explica que si mediara violencia se trataría de lo prescrito en el art. 494 No 20 CP, o bien No 16, en su caso, y en la hipótesis de no mediar violencia debiéramos acudir a lo prescrito en el art. 471 No 1 CP para concluir que, en ningún supuesto, se permite la justicia por la propia mano $^{83}$.

Finalmente, el profesor MAÑAlich, en un acucioso estudio sobre la reconstrucción dogmática de este tipo, concluye que el bien jurídico protegido es la libertad (de pago) y, por lo tanto, existe una correspondencia sistemática entre la realización arbitraria del propio derecho (articulo 494

\footnotetext{
77 Así, Garrido Montr recoge que el ejercicio del derecho legítimo se contempla, pacíficamente, como causal de justificación en la doctrina citando a Novoa, Cousiño, Cury y Etcheverry. Garrido Montt, Mario (2005) Derecho Penal. Parte General. Tomo II. Nociones Fundamentales de la Teoría del Delito. Santiago: Editorial Jurídica de Chile, 478 pp., p. 152.

78 Garrido Montt (1997) 152-153.

79 Garrido Montt (1997) 153: "Esta situación ofrece la posibilidad al titular de un derecho para hacerse justicia de propia mano. Corresponde negar tal eventualidad en el ordenamiento jurídico nacional, por lo menos el empleo de la violencia o de la coacción con tal objetivo, porque hay disposiciones que implícitamente lo descartan”.

80 En este sentido, Soto PiñeIro, Miguel (1989) “Contra Jorge Cosemelli Misle". RCP XXXIX, No 2, pp. 127 y ss.

81 Mera Figueroa, Jorge (1995) Hurto y robo. Santiago: ConoSur, 181 pp., pp. 126-127.

82 Bascuñán Rodríguez, Antonio (2002) "El robo como coacción". Revista Estudios de la Justicia, No 1, pp. 55-125, p. 95.

83 Garrido Montt (1997) 153.
} 
No 20) y la coacción violenta (artículo 494 No 16). Concluyendo, entonces, que "La realización arbitraria del propio derecho constituye una tipificación especifica de un supuesto de coacción mediante violencia: la coacción violenta al pago ${ }^{84}$.

En este escenario, solamente podemos observar la confirmación de una regla general: la autotutela entendida como forma de resolución del conflicto cuya forma de ejecución implica violencia está prohibida por el ordenamiento jurídico ${ }^{85}$.

\section{6) REPOSSESSION, AUTOTUTELA Y NUESTRO ORDENAMIENTO JURÍDICO (A MODO DE CONCLUSIÓN)}

Llegado el punto de afirmar la posibilidad de la aplicación de una institución como la descrita en Derecho comparado entre nosotros, la prudencia llama a aceptarla con alguna prevención y recaudo que, probablemente, van más allá de lo sistemático y jurídico.

En efecto, la autonomía de la voluntad es una fuente inequívoca de generación de obligaciones que permite que las partes arriben por su libertad a los pactos que deseen siempre que no se atente contra el orden público, la ley, ni las buenas costumbres. Dicho aquello, el pacto de una garantía de aseguramiento del cumplimiento de la obligación constituida en el propio objeto no resulta novedoso, ni debiera estar prohibido siempre que se respeten los derechos de colectivos desfavorecidos negocialmente, como los consumidores.

En este contexto, nada se opone a que acreedor y deudor acuerden que, por ejemplo, un automóvil sea la propia garantía de pago de un crédito. Ahora bien, evadir la jurisdicción como forma de pago ante el incumplimiento y dar paso a la autotutela debe observarse con detención y mesura.

Si comprendemos que el acreedor puede apoderarse del bien por su propia mano, debemos, también, establecer cuáles son los límites para que dicha actuación no vulnere los principios generales del ordenamiento jurídico. Básicamente, estamos pensando en que necesariamente la acción física de aprehensión del bien debe encontrarse libre de violencia o coac-

\footnotetext{
84 Mañalich (1999) 124.

85 Es por ello que una de las conclusiones de Alcalá Zamora sigue vigente: "Por otra parte, la autodefensa, que salvo en sus formas procesalizadas, donde funciona una etapa de conocimiento, implica la supresión de esta o su reducción al mínimo, pertenece de lleno al campo de la ejecución, hasta el extremo de que el acto determinante o provocatorio de la misma podríamos, sin violencia, estimarlo como un título ejecutivo extrajudicial a favor del legitimado para emplearla, y por consiguiente, mediante ella el Estado se ahorra asimismo las actuaciones necesarias para el cumplimiento del fallo que se hubiese dictado, de seguirse el correspondiente proceso" (Alcalá Zamora (2000) 56).
} 
ción, para evitar cualquier suspicacia de incumplimiento de las normas penales. Por lo tanto, del mismo modo que sucede en la repossession la toma del bien por parte del acreedor debe realizarse en forma pacífica y sin la oposición del deudor.

En este contexto, entonces, una concepción moderna de la autotutela pasa necesariamente por despojar del concepto justicia por la propia mano la ejecución mediante actos violentos. Si conseguimos comprender que esa justicia, hoy en día, debe desarrollarse en términos pacíficos y que su objetivo es evitar los males derivados de la aglomeración que sufre el sistema judicial civil, daremos un paso hacia una sociedad más madura, moderna y democrática que acepta que los particulares resuelvan sus controversias civiles en forma directa, sosegada y serena. Probablemente, significaría alivianar las cargas de la jurisdicción y entregaría una respuesta fugaz y adecuada para conseguir que el tráfico comercial mejore, en las expectativas que el acreedor puede reparar su patrimonio en caso que el deudor no pueda afrontar el pago.

Sin embargo, este tipo de decisiones legislativas no están exentas de polémica $y$, en especial, de estudios sociológicos rigurosos que sean capaces de vislumbrar si la transferencia de la jurisdicción a la ciudadanía puede, finalmente, generar más trastornos que ventajas. No debemos olvidar que los deudores, probablemente, no se sientan satisfechos ante una decisión unilateral de restablecimiento del orden y, en aquella situación, puedan emprender acciones motivadas por la venganza que, precisamente, es el motor de la autotutela en el sentido más pernicioso del término.

En conclusión, entonces, la repossession es una figura interesante a explorar en profundidad que, sin embargo, ha de contar con estudios más allá de lo técnico legislativo que puedan dar cuenta de un trasplante exitoso. De lo contrario, el riesgo de rechazo puede, a la postre, generar más conflictos que soluciones adecuadas y traspasar un problema civil, a la jurisdicción penal.

\section{BIBLIOGRAFÍA}

Alcalá Zamora, Niceto (2000) Proceso, autocomposición y autodefensa. Contribución al estudio de los fines del proceso. México D.F: Universidad Nacional Autónoma de México, 314 pp.

Alsina, Hugo (2001) Fundamentos de Derecho Procesal, Vol. 4. México D.F.: Editorial Jurídica Universitaria, 583 pp.

Alvarado Velloso, Adolfo y Aguila Grados, Guido (2011) Lecciones de Derecho Procesal Civil. Lima: Editorial San Marcos, 838 pp.

Bajo Fernández, Miguel (1976) La realización arbitraria del propio derecho. Madrid: Ed. Civitas, 89 pp. 
Bascuñán Rodríguez, Antonio (2002) “El robo como coacción”. Revista Estudios de la Justicia, No 1, pp. 55-125.

Calamandrei, Piero (1973) Instituciones de Derecho Procesal Civil. Buenos Aires: Ediciones Jurídicas Europa-America, 421 pp.

Carnelutti, Francesco (1973) Instituciones del Proceso Civil. Traducción Sentís Melendo, Vol. 1. Buenos Aires: Ediciones Jurídicas EuropaAmérica, 557 pp.

Carnelutti, Francesco (2001) Cuestiones sobre el proceso penal, Vol. 2. México D.F.: Editorial Jurídica Universitaria, 265 pp.

Caro Garzón, Octavio Augusto (2006) "La doctrina Bush de la guerra preventiva ¡evolución del ius ad bellum o vuelta al medioevo?”. Revista Facultad de Derecho y Ciencias Politicas, Vol. 35, No 105, pp. 399-429.

Castillejo Manzanares, Raquel (2014) Del poder de disposición de las partes sobre el proceso civil y sobre sus pretensiones. Madrid: La Ley, 324 pp.

Colombo Campbell, Juan (1997) Los actos procesales. Tomo I. Santiago: Editorial Jurídica de Chile, 333 pp.

Couture, Eduardo (1989) Estudios de Derecho Procesal Civil. Tomo I, La Constitución y el Proceso Civil, 3a Ed. Buenos Aires: Ediciones Depalma, 366 pp.

Cury, Enrique (2005) Derecho Penal Parte General, tomo I. Santiago: Editorial Jurídica de Chile, 812 pp.

Etcheberry, Alfredo (1999) Derecho Penal. Parte General. Santiago: Editorial Jurídica de Chile, $361 \mathrm{pp}$.

Garrido Montt, Mario (2005) Derecho Penal. Parte General. Tomo II. Nociones Fundamentales de la Teoría del Delito. Santiago: Editorial Jurídica de Chile, 478 pp.

Gimeno Sendra, Vicente (2014) Introducción al Derecho Procesal. Madrid: Colex, 357 pp.

Gómez Colomer, Juan Luis (2014) "Medios de solución de los conflictos colectivos". En Montero Aroca et al.: Derecho Jurisdiccional I. Valencia: Tirant lo Blanch, 355 pp.

Iglesias, Juan (2001) Derecho Romano, 13a Ed. Madrid: Ariel, 520 pp.

Mañalich Raffo, Juan Pablo (2009) Autotutela del accedor y protección penal del deudor. La realización arbitraria del propio derecho frente a los delitos contra la libertad, la propiedad y el patrimonio. Santiago: Ediciones Jurídicas de Santiago, 134 pp.

Maturana Miquel, Cristian y López Montero, Raúl (2010) Derecho Procesal Penal. Santiago: Abeledo Perrot-LegalPublishing, 513 pp.

Mera Figueroa, Jorge (1995) Hurto y robo. Santiago: ConoSur, 181 pp.

Montero Aroca, Juan (2006) La nueva Ley de Enjuiciamiento Civil española, los poderes del juez y la oralidad. Valencia: Tirant lo Blanch, $438 \mathrm{pp}$. 
Muñoz Conde, Francisco (2001) Derecho Penal. Parte Especial. Valencia: Tirant lo Blanch, $1039 \mathrm{pp}$.

Nieva Fenoll, Jordi (2014) Derecho procesal I. Introducción. Madrid: Marcial Pons, 310 pp.

Núńez Ojeda, Raúl y Pérez Ragone, Álvaro (2013) Manual de Derecho Procesal Civil. Parte General. Santiago: Thomson Reuters, 486 pp.

Politoff, Sergio; Matus, Jean Pierre y Ramírez, Ma Cecilia (2008) Lecciones de Derecho Penal Chileno. Santiago: Editorial Jurídica de Chile, 613 pp.

Serra Domínguez, Manuel (2008) Jurisdicción, acción y proceso. Barcelona: Atelier, $260 \mathrm{pp}$.

Taruffo, Michele (2009) Páginas sobre justicia civil. Madrid Barcelona Buenos Aires: Marcial Pons, 599 pp.

Twining, William (1993) "Alternative to What? Theories of Litigation, Procedure and Dispute Settlement in Anglo-American Jurisprudence: Some Neglected Classics". The Modern Law Review, 56:3, pp. 380-392.

Vallespín Pérez, David (2002) El modelo constitucional de juicio justo en el ámbito del proceso civil. Barcelona: Atelier, $170 \mathrm{pp}$.

Wegmann Stockebrand, Adolfo (2009) "Algunas consideraciones sobre la prohibición del pacto comisorio y el pacto marciano". Revista Chilena de Derecho Privado, No 13, pp. 95-122. 